\title{
Reaktancyjne kompensatory czwórnikowe dla przebiegów monoharmonicznych
}

Streszczenie. W artykule przedstawiono metodę pełnej kompensacji biernego prądu źródła rzeczywistego, monoharmonicznego przy pomocy czwórnikowego układu dopasowujacego. Czwórnik, w przeciwieństwie do kompensatora dwójnikowego, potrafi uniezależnić obwód zasilania od obwodu odbiornika i zapewnić źródłu optymalne warunki pracy przy jednoczesnym zachowaniu niezmienionych wartości napięcia i prądu odbiornika. Przez optymalne warunki pracy źródła należy tu rozumieć całkowitą minimalizację wartości skutecznej prądu źródła zasilania do tzw. prądu aktywnego niosącego całą moc czynną do odbiornika.

Abstract. This paper presents method for full compensation of reactive current of the real monoharmonic power source with the use of a four terminal network as a matching circuit. The four-terminal network, as opposed to the two-terminal network compensator, is capable to make power supply circuit independent from the receiver circuit. Then it ensure optimum source operating conditions maintaining at the same time unchanged voltage and current of the load. Obtaining the optimum source operating condition usually means the total minimization of the source current RMS value as to get so called active current of source, that transmits the all active power to the receiver. (Four-terminal network reactive compensators for sinusoidal signals).

Słowa kluczowe: moc czynna, kompensacja, źródło monoharmoniczne, czwórnik.

Keywords: active power, compensation, monoharmonic source , four-terminal network.

\section{Wstęp}

Stosowana powszechnie kompensacja prądu biernego źródła jednym kondensatorem równoległym nie minimalizuje strat przesyłu ani wartości skutecznej prądu źródła. Jeżeli uwzględni się znane parametry zastępcze źródła energii to minimalizacja prądu i strat przesyłu nie daje się zrealizować za pomocą dwójnikowego kompensatora biernego $[2,3,4,5]$. W pracy został przedstawiony czwórnikowy układ kompensujący prąd źródła, który zapewnia optymalne warunki pracy źródła, nominalne warunki pracy odbiornika i realizowalność układu kompensującego jedynie przy pomocy elementów reaktancyjnych.

\section{Optymalne warunki pracy źródła}

Za warunek optymalnej pracy źródła przyjmuje się przeważnie osiągnięcie minimalnej wartości skutecznej prądu źródła (strat przesyłu) przy zadanej mocy czynnej opuszczającej źródło energii, który można zapisać w następującej postaci:

$$
\begin{gathered}
\mathrm{II}^{*} \rightarrow \min \\
\mathrm{P}=\operatorname{real~I}^{*} \mathrm{E}-\mathrm{R}_{\mathrm{E}} \mathrm{I}^{*} \mathrm{I}
\end{gathered}
$$

gdzie: $\quad R_{E}=0,5\left(Z_{E}+Z_{E}^{*}\right)$

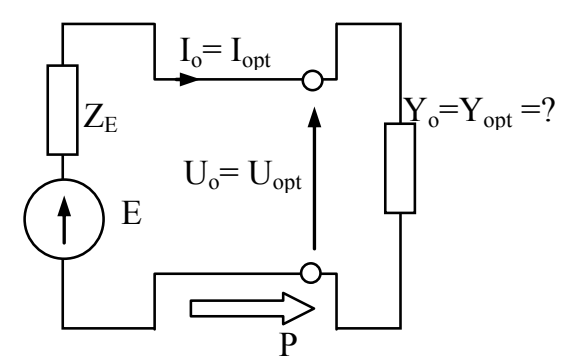

Rys. 1. Schemat ilustrujący minimalizację wartości skutecznej prądu źródła

Znane jest rozwiązanie tego problemu, którym jest prąd zasilania będący w fazie z SEM źródła

$$
\mathrm{I}=\mathrm{G}_{\mathrm{e}} \mathrm{E}
$$

gdzie $G_{e}$ - przewodność zastępcza SEM

Spełnienie przez ten prąd warunku mocy, czyli równania

(3)

lub

$$
\mathrm{R}_{\mathrm{E}} \mathrm{I}^{*} \mathrm{I}-\operatorname{real} \mathrm{I}^{*} \mathrm{E}+\mathrm{P}=0
$$

$\mathrm{R}_{\mathrm{E}} \mathrm{G}_{\mathrm{e}}{ }^{2}-\mathrm{G}_{\mathrm{e}}+\frac{P}{|E|^{2}}=0$

pozwala na obliczenie przewodności optymalnej

$$
\mathrm{G}_{\mathrm{opt}}=\frac{1-\sqrt{1-\frac{P}{P_{\max }}}}{2 R_{E}}
$$

gdzie moc maksymalna dana jest wzorem

$$
\mathrm{P}_{\max }=\mathrm{R}_{\mathrm{E}}=\frac{|E|^{2}}{4 R_{E}}
$$

Wynika stąd że admitancję kompensatora $Y_{k}$ połączoną równolegle $z$ admitancją obciążenia $Y_{L}$ obliczyć można $z$ zależności

$$
\mathrm{Y}_{\mathrm{k}}=\mathrm{Y}_{\mathrm{opt}}-\mathrm{Y}_{\mathrm{L}}
$$

$\operatorname{przy}$ czym : $\frac{1}{G_{e}}=1 / Y_{\mathrm{opt}}+\mathrm{Z}_{\mathrm{E}}$

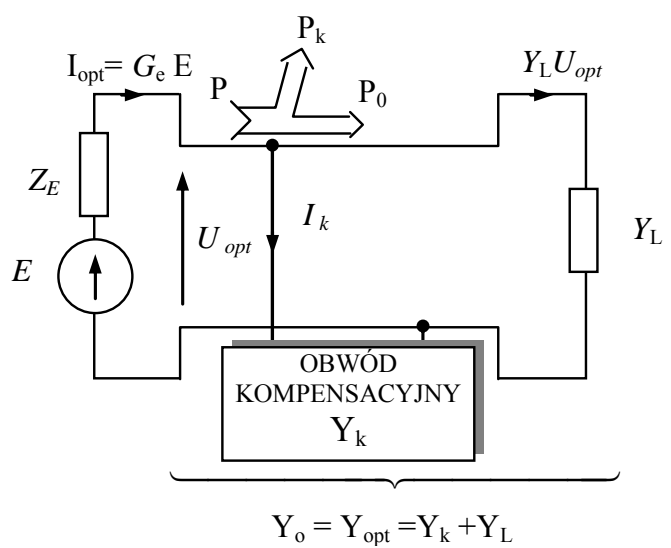

Rys. 2. równoległy kompensator dwójnikowy i admitancja $Y_{0}$ widziana przez źródło 
Jednak $z$ analizy wykresu wektorowego admitancji od parametrów odbiornika widzianego przez źródło $Y_{0}=G_{0}+j$ $B_{\circ}$ wynika że admitancja kompensatora $Y_{k}=G_{k}+j B_{k}$ ma najczęściej część rzeczywistą różną od zera $G_{k} \neq 0$

A więc kompensator jest dwójnikiem czynnym [1,2] lub stratnym.

Sytuację tą ilustrują poniższe wykresy izolinii mocy i izolinii wartości skutecznej prądu źródła we współrzędnych odbiornika
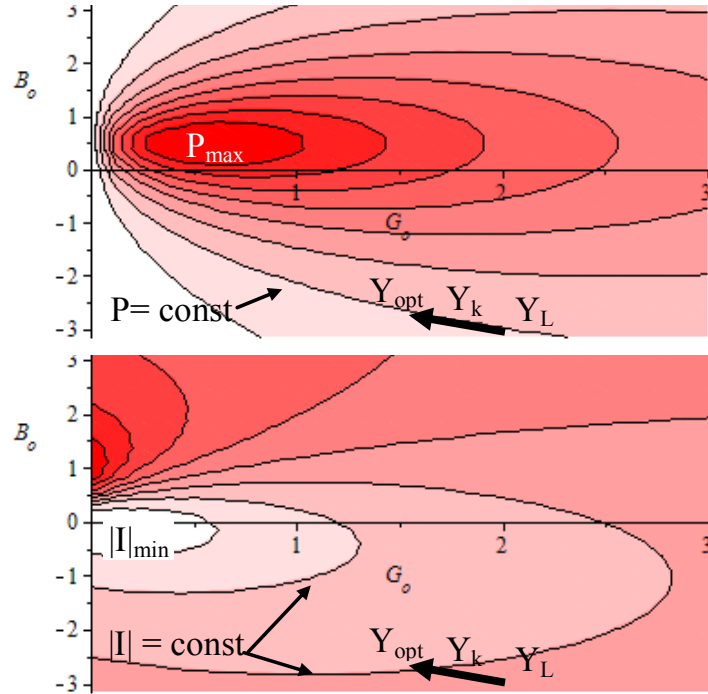

Rys. 3. Izolinie mocy i wartości skutecznej prądu źródła we współrzędnych admitancji odbiornika widzianej przez źródło

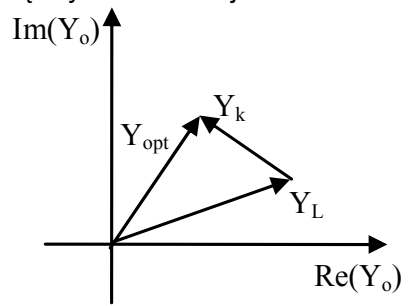

Rys. 4. Wykresy ilustrujące zmianę admitancji obciążenia źródła w skutek kompensacji, tj. zależność między $Y_{\mathrm{opt}} \mathrm{Y}_{\mathrm{L}}$ a $Y_{\mathrm{k}}$

Podobny problem występuje przy kompensacji szeregowej

Impedancja kompensatora $Z_{k}$ połączonego szeregowo $z$ impedancją obciążęnia $Z_{\mathrm{L}}$ obliczyć można z zależności

(6)

$$
\begin{aligned}
\frac{1}{G_{e}} & =Z_{\text {opt }}+Z_{\mathrm{E}} \\
Z_{\mathrm{k}} & =Z_{\mathrm{opt}}-\mathrm{Z}_{\mathrm{L}}
\end{aligned}
$$

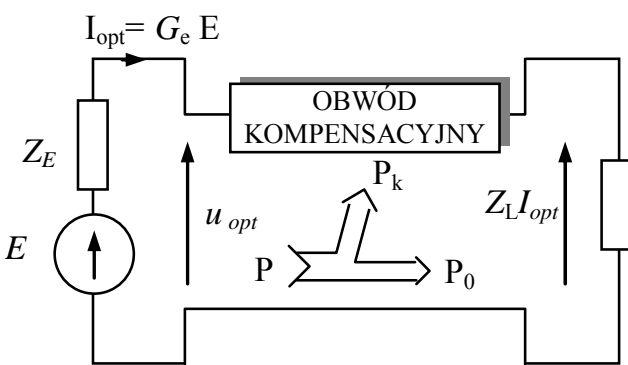

Rys. 5. szeregowy kompensator dwójnikowy

Jednak $z$ analizy wykresu wektorowego we współrzędnych impedancji odbiornika $\mathrm{R}_{\mathrm{o}}, \mathrm{X}_{\mathrm{o}}$

$\left(Z_{0}=R_{0}+j X_{0}\right)$ wynika że impedancja kompensatora

$Z_{k}=R_{k}+j X_{k}$ ma najczęściej część rzeczywistą różną od zera $\operatorname{Re}\left(Z_{k}\right)=R_{k} \neq 0$

A więc kompensator jest dwójnikiem czynnym lub stratnym
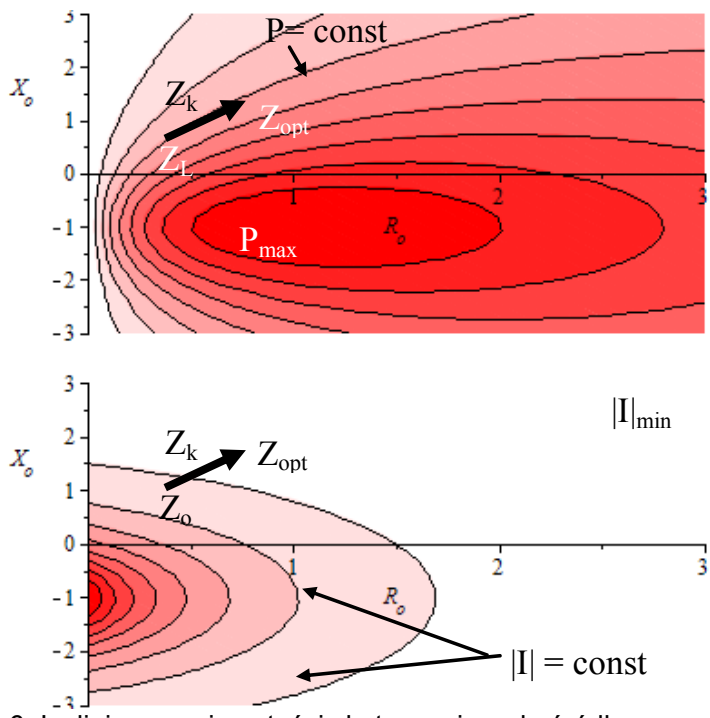

Rys. 6. Izolinie mocy i wartości skutecznej prądu źródła we współrzędnych impedancji odbiornika widzianego przez źródło

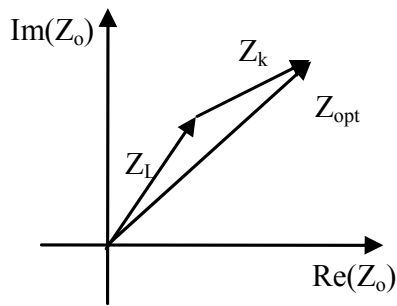

Rys. 7. Wykresy ilustrujące zmianę impedancji obciążenia źródła w skutek kompensacji tj. zależność między $Z_{o p t} Z_{\mathrm{L}}$ a $Z_{\mathrm{k}}$

\section{Kompensator czwórnikowy}

Czwórnikowy obwód kompensacyjny jest w stanie całkowicie odseparować zasilanie od odbiornika dzięki czemu potrafi stworzyć niezależne, optymalne warunki pracy dla źródła i odbiornika. Zapobiega tez sytuacji, w której kompensator musi wytwarzać lub wytracać moc czynną aby zapewnić źródłu optymalne warunki pracy.

Jednak nie zawsze możliwa jest jego realizacja za pomocą elementów reaktancyjnych.

Kompensator czwórnikowy kształtu $\Gamma-\mathrm{w}$ ogólności nie będzie realizowalny przy pomocy elementów reaktancyjnych.

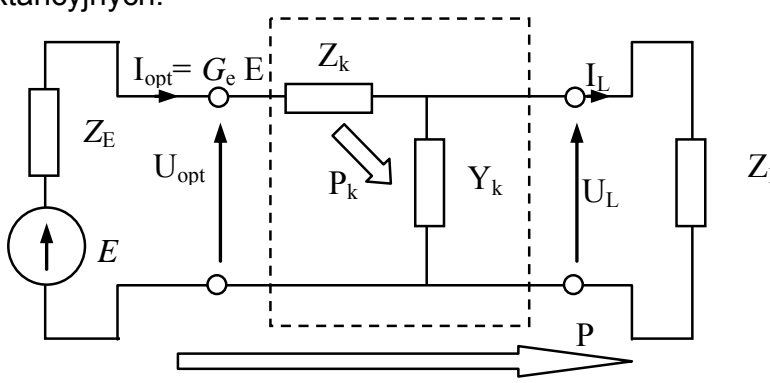

Rys. 8. kompensator czwórnikowy bierny

Chociaż $w$ całości będzie on bierny to jedna $z$ jego gałęzi będzie pobierać a druga oddawać moc czynną.

\section{Kompensator czwórnikowy reaktancyjny}

Kompensator czwórnikowy musi mieć co najmniej 3 gałęzie aby można go było zrealizować przy pomocy samych elementów reaktancyjnych.

Będzie on wtedy również w całości bierny .

Aby wyznaczyć parametry takiego kompensatora wystarczy znać optymalne warunki pracy źródła tj. wartość prądu optymalnego (minimalnego) $l_{\text {opt }} \mathrm{i}$ admitancję obciążenia $Y_{L}$ 


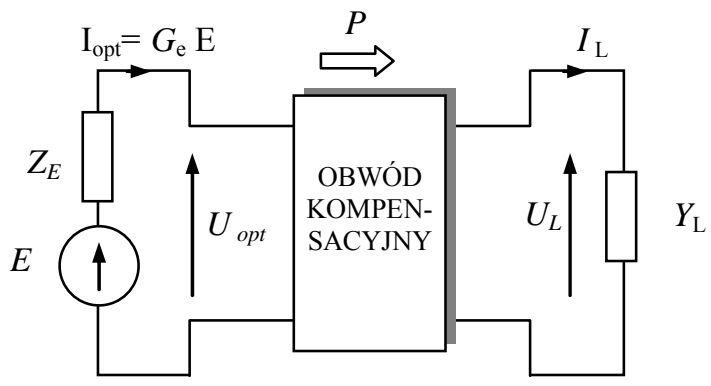

Rys. 9. kompensator czwórnikowy reaktancyjny

Z warunku minimalnej wartości skutecznej prądu źródła (strat przesyłu) przy zadanej mocy czynnej opuszczającej źródło energii (1) otrzymujemy wartość przewodności zastępczej $\mathrm{G}_{\mathrm{e}}$ widzianej przez SEM. Zatem cały układ z punktu widzenia SEM sprowadzamy do czwórnika o admitancji wejściowej równej $\mathrm{G}_{\mathrm{e}}$

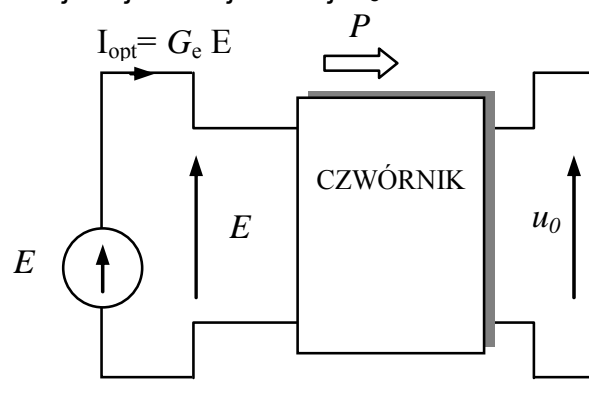

Rys. 10. Układ zastępczy widziany przez SEM po optymalizacji

\section{Kompensator kształtu T}

Jedną z możliwych realizacji reaktancyjnego czwórnika kompensacyjnego jest czwórnik kształtu $\mathrm{T}$ przedstawiony na rysunku 11.

Opisując cały układ otrzymujemy następujące zależności

$$
\left[\begin{array}{c}
E \\
I_{\text {opt }}
\end{array}\right]=\left[\begin{array}{c}
E \\
G_{e} E
\end{array}\right]=
$$

$\left[\begin{array}{cc}1 & Z_{E} \\ 0 & 1\end{array}\right]\left[\begin{array}{cc}1 & j X_{1} \\ 0 & 1\end{array}\right]\left[\begin{array}{cc}1 & 0 \\ j B & 1\end{array}\right]\left[\begin{array}{cc}1 & j X_{2} \\ 0 & 1\end{array}\right]\left[\begin{array}{cc}1 & 0 \\ 1 / Z_{o} & 1\end{array}\right]$

$$
\left[\begin{array}{c}
U_{o} \\
0
\end{array}\right]
$$

lub

(8)

stąd

$$
\left[\begin{array}{c}
E \\
G_{e} E
\end{array}\right]=\mathrm{A}\left[\begin{array}{c}
U_{o} \\
0
\end{array}\right]
$$

$$
\frac{1}{G_{e}}=\frac{A_{11}}{A_{21}}
$$

Spełnienie warunku optymalnej pracy źródła wymaga aby admitancja widziana przez SEM była przewodnością $\mathrm{G}_{\mathrm{e}}$, co można zapisać w formie dwóch równań

(10) $\operatorname{Re}\left(\frac{A_{11}}{A_{21}}\right)=\operatorname{Re}\left(Z_{E}+j X_{1}+\frac{Z_{o}+j X_{2}}{j B\left(Z_{o}+j X_{2}\right)+1}\right)=\frac{1}{G_{e}}$

$$
\operatorname{Im}\left(\frac{A_{11}}{A_{21}}\right)=\operatorname{Im}\left(Z_{E}+j X_{1}+\frac{Z_{o}+j X_{2}}{j B\left(Z_{o}+j X_{2}\right)+1}\right)=0
$$

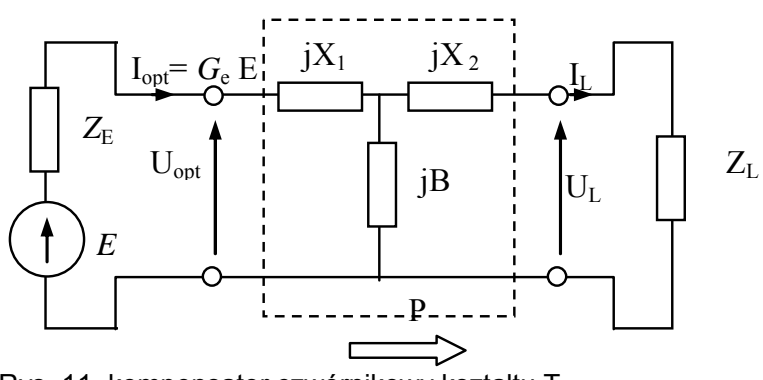

Rys. 11. kompensator czwórnikowy kształtu $T$

Rozwiązanie tych dwóch równań musi jednak zależeć od trzeciego parametru czwórnika np. od susceptancji B

$$
\begin{gathered}
X_{1}(\mathrm{~B})=-\mathrm{X}_{\mathrm{E}}+\frac{1}{B} \pm \sqrt{\Delta R} \sqrt{\frac{1}{R o B^{2}}-\Delta R} \\
X_{2}(\mathrm{~B})=-\mathrm{X}_{\mathrm{o}}+\frac{1}{B} \pm \sqrt{R o} \sqrt{\frac{1}{\Delta R B^{2}}-R o}
\end{gathered}
$$

gdzie:

$$
\begin{aligned}
& \Delta \mathrm{R}=\frac{1}{G_{e}}-\mathrm{R}_{\mathrm{E}}>0 \\
& \text { rozwiązanie będzie rzeczywiste jeżeli } \\
& -\frac{1}{\sqrt{\operatorname{Ro\Delta R}}}<\mathrm{B}<\frac{1}{\sqrt{\operatorname{Ro\Delta R}}}
\end{aligned}
$$

\section{Kompensator kształtu $\Pi$}

Drugą z możliwych realizacji reaktancyjnego czwórnika kompensacyjnego jest czwórnik kształtu $\Pi$, przedstawiony na rysunku 12.

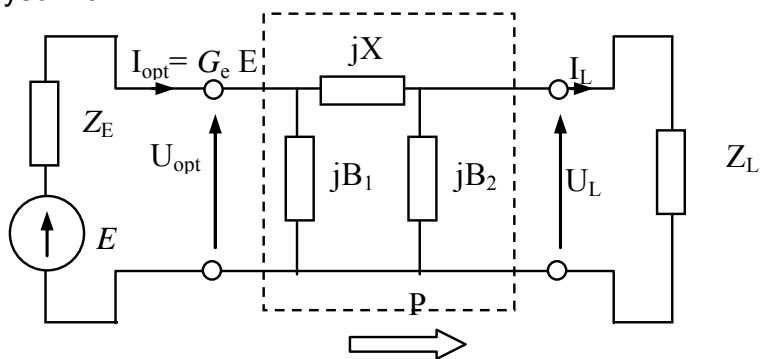

Rys. 12. kompensator czwórnikowy kształtu П

Równania są następujące

$$
\left[\begin{array}{c}
E \\
I_{\text {opt }}
\end{array}\right]=\left[\begin{array}{c}
E \\
G_{e} E
\end{array}\right]=
$$

$\left[\begin{array}{cc}1 & Z_{E} \\ 0 & 1\end{array}\right]\left[\begin{array}{cc}1 & 0 \\ j B_{1} & 1\end{array}\right]\left[\begin{array}{cc}1 & j X \\ 0 & 1\end{array}\right]\left[\begin{array}{cc}1 & 0 \\ j B_{2} & 1\end{array}\right]\left[\begin{array}{cc}1 & 0 \\ Y_{L} & 1\end{array}\right]\left[\begin{array}{c}U_{o} \\ 0\end{array}\right]$

lub

stąd

$$
\left[\begin{array}{c}
E \\
G_{e} E
\end{array}\right]=\mathrm{A}\left[\begin{array}{c}
U_{o} \\
0
\end{array}\right]
$$

Admitancja widziana przez SEM musi być równa przewodności $G_{e}$, zatem

$$
\begin{gathered}
\operatorname{Re}\left(\frac{A_{11}}{A_{21}}\right)= \\
=\operatorname{Re}\left(Z_{E}+\frac{1+j X\left(j B_{2}+Y_{o}\right)}{j B_{1}\left(1+j X\left(j B_{2}+Y_{o}\right)\right)+j B_{2}+Y_{o}}\right)=\frac{1}{G_{e}}
\end{gathered}
$$




$$
\begin{gathered}
\operatorname{Im}\left(\frac{A_{11}}{A_{21}}\right)= \\
=\operatorname{Im}\left(Z_{E}+\frac{1+j X\left(j B_{2}+Y_{o}\right)}{j B_{1}\left(1+j X\left(j B_{2}+Y_{o}\right)\right)+j B_{2}+Y_{o}}\right)=0
\end{gathered}
$$

Rozwiązanie tych dwóch równań zależy od trzeciego parametru czwórnika $\mathrm{np}$. od reaktancji $X$

$$
B_{1}(\mathrm{X})=\frac{1}{X}+(1 \pm \mathrm{K}) \frac{X_{E}}{\Delta Z^{2}}
$$

$B_{2}(\mathrm{X})=\frac{1}{X}-\mathrm{B}_{\circ}+\mathrm{G}_{\circ} \frac{X_{E}}{\Delta R}-\frac{1}{1 \pm K} \frac{\Delta Z^{2}}{\Delta R} \frac{X^{2} G o-\Delta R}{X_{E} X^{2}}$

gdzie:

$\Delta \mathrm{R}=\frac{1}{G_{e}}-\mathrm{R}_{\mathrm{E}}>0 ; \Delta \mathrm{Z}^{2}=\Delta \mathrm{R}^{2}+\mathrm{X}_{\mathrm{E}}^{2}>0$

$\mathrm{K}=\sqrt{\frac{\Delta R}{G o}} \frac{\sqrt{\Delta Z^{2}-X^{2} G o \Delta R}}{X_{E} X}$

rozwiązanie jest rzeczywiste w zakresie

$$
-\frac{\Delta Z}{\sqrt{G o \Delta R}}<\mathrm{X}<\frac{\Delta Z}{\sqrt{G o \Delta R}}
$$

\section{Przykłady obliczeniowe}

Rozważmy minimalizację prądu w układzie źródło odbiornik z rys 13 .

Przed minimalizacja:

$$
\begin{gathered}
|\mathrm{I}|=|\mathrm{E}| /\left|\mathrm{Z}_{\mathrm{E}}+\mathrm{Z}_{\mathrm{o}}\right|=0.141 \\
|\mathrm{U}|=|\mathrm{I}|\left|\mathrm{Z}_{\mathrm{o}}\right| \|=0.087
\end{gathered}
$$

oraz moc maksymalna źródła ze wzoru (4) jest równa

$$
\mathrm{P}_{\max }=\frac{|E|^{2}}{4 R_{E}}=\frac{1}{4}
$$

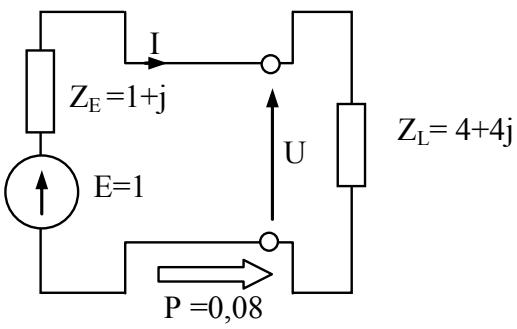

Rys. 13. układ zasilania i odbiornik przed optymalizacją

1) Kompensator czwórnikowy kształtu $T$

Przewodność $G_{e}$ wyznaczamy ze wzoru (9) (rys. 11)

$$
\mathrm{G}_{\mathrm{e}}=0.087
$$

Możliwe są dwa rozwiązania na $\mathrm{X}_{1}$ i $\mathrm{X}_{2}$ od parametru $\mathrm{B}$

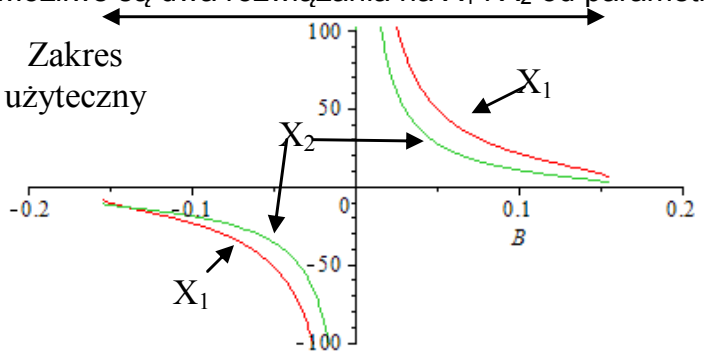

Rys. 14. Rozwiązanie A

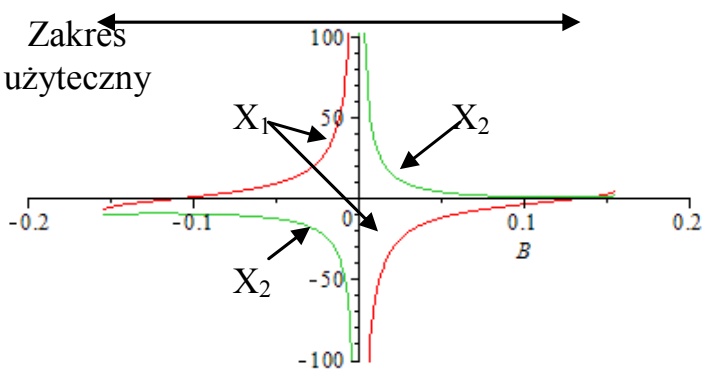

Rys. 15. Rozwiązanie B

Wybieramy rozwiązanie $(A)$ oraz $B=0.05$

Stąd odczytujemy

$\mathrm{X}_{1}=49.6479$,

$X_{2}=27.682$

Po dołączeniu kompensatora wartość skuteczna prądu źródła ze wzoru (14) jest równa

$$
\mathrm{I}_{\mathrm{opt}}=0.087
$$

A napięcie i prąd obciążenia pozostały bez zmian $\left(\mathrm{I}_{\mathrm{L}}=\right.$ $\left.0.141, U_{L}=0.087\right)$.

Zatem bezstratny i reaktancyjny czwórnik całkowicie kompensujący prąd bierny źródła istnieje i jest przedstawiony na rys 16

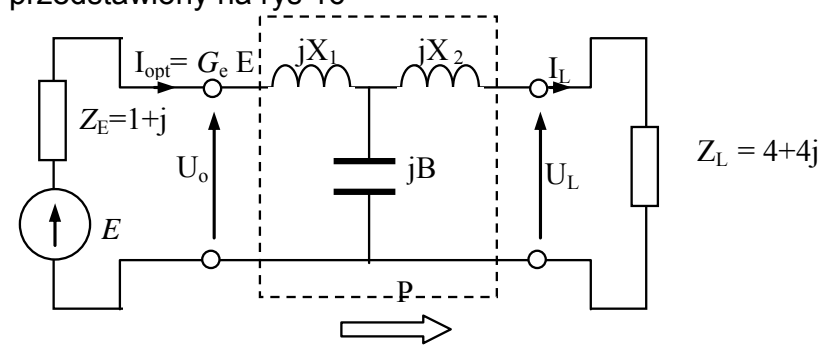

Rys. 16. układ zasilania i odbiornik po optymalizacji i dołączeniu reaktancyjnego kompensatora czwórnikowego

\section{Podsumowanie}

Czwórnikowe układy dopasowujące (kompensacyjne) lepiej nadają się do zadań optymalizacji (kompensacji) w układach elektrycznych niż układy dwójnikowe. Czwórnik przynajmniej $z$ trzema gałęziami jest w stanie całkowicie zminimalizować prąd źródła a jego budowa możliwa jest przy użyciu gałęzi czysto reaktancyjnych. Zatem w przeciwieństwie do kompensatorów dwójnikowych jest łatwo realizowalny bo nie wymaga wprowadzania gałęzi wytracającej lub dostarczającej moc do układu.

Autor: dr inż. Marcin Jaraczewski, e-mail: jaracz@pk.edu.pl., Politechnika Krakowska, Wydział Inżynierii Elektrycznej i Komputerowej, Katedra Elektrotechniki i Elektroniki ul. Warszawska 24

\section{LITERATURA}

[1] Cimbals, R. Krievs, O. Ribickis, A static synchronous compensator for displacement power factor correction under distorted mains voltage conditions, Elektronika ir Elektrotechnika, no.4(110), 2011 April, p.71(6) (ISSN: 13921215).

[2] Siwczyński M. Jaraczewski M.: Metody optymalizacyjne teorii mocy, przegląd zasad minimum dla obwodu jednooczkowego JUEE 2002. z.1/2, 5-15.

[3] Dębowski K., Pasko M.: Minimalizacja prądów fazowych w układach n-fazowych n-przewodowych z nieliniowymi odbiornikami połaczonymi w uogólniona gwiazde. Prace Naukowe Politechniki Śląskiej, "Elektryka", Rok LIII, Z. 2 (202), 2007, s.89-100.

[4] Siwczyński M. Jaraczewski M.: Zasada podobieństwa w równaniach optymalizacyjnych teorii mocy $\mathrm{i}$ energii - zadania łączone Przegląd Elektrotechniczny (Electrical Review) R. 87 NR $5 / 2011$

[5] Pasko M.: Opis właściwości energetycznych, energetycznojakościowych obwodów elektrycznych z przebiegami niesinusoidalnymi okresowymi, Przegląd Elektrotechniczny, nr 5s, 2002, str. 23-40, 